\title{
ESPIRITUALIDAD DEL SACERDOTE DIOCESANO SECULAR (y IV)
}

DOI: https://doi.org/10.52039/seminarios.v51i178.685

Autor: Florentino Muñoz Muñoz. Sacerdote. Profesor de Teología en el Seminario Mayor de Cáceres y Vicario Episcopal para el Clero de la diócesis de Coria-Cáceres.

Aborda en esta $4^{a}$ parte las raices humanas, la dimensión bautismal y el perfil peculiar del sacerdote diocesano secular, con las claves para su espiritualidad en el Sacramento del Orden, en su capacidad de relación - "hombre de comunión" - en múltiples ámbitos.

\section{CAPÍTULO OCTAVO: RASGOS MARIANOS DE LA ESPIRI- TUALIDAD DEL SACERDOTE}

La espiritualidad del sacerdote incluye también "la dimensión mariana" (cf. RM 45 y 46). Por eso, el sacerdote ha de acoger en su vida a María como a su Madre, que será objeto de sus continuas atenciones y de sus oraciones ${ }^{1}$.

${ }^{1}$ Congregación para el Clero: "Directorio para el ministerio y la vida de los Presbiteros", (n. 68). 


\section{La espiritualidad del Sacerdote, como cristiano, tiene rasgos marianos}

- La obediencia desinteresada. María creyó a Dios entregándole su propio yo femenino en el Misterio de la Anunciación.

- La contemplación. Sólo una contemplativa como María puede descubrir que la misericordia de Dios alcanza a todas las generaciones de la historia.

- La evangelización. María, estrella de la nueva evangelización, "no fue una mujer replegada celosamente sobre su propio Hijo divino, sino que 1levó la salvación a la casa de Isabel" y "con su acción favoreció la fe de la comunidad apostólica en Cristo-Jesús y cuya función maternal se dilató asumiendo sobre el Calvario dimensiones universales"2.

- La esperanza activa y dinámica. María "no defrauda ninguna de las aspiraciones profundas de los hombres de nuestro tiempo, e incluso les ofrece el modelo consumado del discípulo del Señor: obrero de la ciudad terrena y temporal, al mismo tiempo, peregrino incansable hacia la ciudad celeste y eterna; promotor de la justicia que libera al oprimido y de la caridad que socorre al necesitado, pero sobre todo testigo activo del amor que edifica a Cristo en los corazones"3.

- La opción por los pobres. María afirma en el Magnificat que "no se puede separar la verdad sobre Dios de su amor preferencial por los pobres y los humildes"4.

- La fortaleza. María "conoció de cerca la pobreza y el sufrimiento, la huida y el exilio, situaciones que no pueden escapar a quien pretenda secundar con espíritu evangélico las energías liberadoras del hombre y de la sociedad" (MC 37).

- La misericordia. María en el Magnificat proclamó que la misericordia de Dios se extiende por todas las generaciones.

- El servicio a la justicia. María "aun habiéndose abandonado a la voluntad del Señor, lejos de ser una mujer pasivamente sumisa o de una religiosidad alienante, fue una mujer que no dudó en afirmar que Dios es vengador de los humildes y de los oprimidos y derriba del trono a los poderosos del mundo" (MC, n. 37).

2 Pablo VI: "Marialis Cultus", n.37.

3 Pablo VI: "Marialis Cultus", n.37).

4 Juan Pablo II: "Redemptoris Mater",n.37; cf. Sda. Cong.para la Doctrina de la fe: "Instr.sobre Libertad cristiana y liberación" (22-.II-1986). 


\section{La espiritualidad específica del sacerdote tiene rasgos marianos}

"Veneren y amen los presbíteros con filial devoción y veneración a esta Madre del Sumo y Eterno Sacerdote, Reina de los Apóstoles y auxilio de su ministerio" (PO 18).

Los rasgos marianos más significativos de la espiritualidad específica del Sacerdote son los siguientes:

- Conocer a María en el misterio de Jesucristo y en el misterio de la Iglesia. "En María, Madre del Sumo y Eterno Sacerdote, el sacerdote toma conciencia de ser con Ella "instrumento de comunicación salvífica entre Dios y los hombres", aunque de modo diferente: la Stma. Virgen mediante la Encarnación, el sacerdote mediante el poder del Orden 5 .

- Amar a María como Madre de Cristo-Jesús y como el mejor fruto de la Redención.

- Contemplar a María como Madre de la Iglesia que nos pide que colaboremos en la "función materna" de la Iglesia-Madre que se caracteriza por la acogida, la creatividad, la ternura, la cordialidad, la alegría, el servicio.

- Imitar a María en su asociación esponsal con Cristo, en su contemplación de la Palabra y en su fidelidad generosa a la acción del Espíritu Santo. "Ella, guiada por el Espíritu Santo, se entregó totalmente al misterio de la redención de los hombres" (PO 18).

- Celebrar a María en el ámbito del misterio pascual de Jesucristo, especialmente en la Eucaristía, en la Liturgia de las horas, en el Año litúrgico. El sacerdote ha de tomar conciencia de "la cercanía de la Señora", como presencia operante junto a la cual la Iglesia quiere vivir el misterio de Cristo"6.

- Invocar a María pidiéndole su intercesión para el camino de configuración con Cristo Buen Pastor y para el proceso de la evangelización. El sacerdote necesita la protección, la ayuda y el amparo de la Virgen María.

- En la penetración del misterio de Cristo, viene en ayuda del sacerdote la Virgen María, asociada al Redentor, porque "cuando celebramos la Santa Misa, en medio de nosotros está la Madre del Hijo de Dios y nos

\footnotetext{
5 Pablo VI: Catequesis, 7-X-1964).

6 Pablo VI: "Marialis Cultus" nn.11,32, 50,56).
} 
introduce en el misterio de su ofrenda de redención. De este modo se convierte en mediadora de las gracias que brotan de esta ofrenda para la Iglesia y para todos los fieles".

San Juan de Ávila exhortaba a los sacerdotes con estas hermosas palabras: "mirémonos de pies a cabeza, ánima y cuerpo, y vernos hemos hechos semejantes a la sacratísima Virgen María, que con sus palabras trajo a Dios a su vientre...Y el sacerdote le trae con las palabras de la consagración"7.

"El Presbítero, por tanto, ha de mirar a María si quiere ser un ministro humilde, obediente y casto, que pueda dar testimonio de caridad a través de la donación total al Señor y a la Iglesia" (PO 18).

${ }^{7}$ S. Juan de Ávila, Plática $I^{a}$ a los sacerdotes. 


\section{CAPÍTULO NOVENO: EL PROYECTO DE VIDA ESPIRITUAL DEL PRESBÍTERO}

El mundo ha cambiado mucho en los últimos años. Se afirma que vivimos en una época llamada "post": post-moderna, post-industrial, postcristiana...

Vivimos en un tiempo de búsqueda de nuevos paradigmas, mediaciones...Por eso, lo que se propone en estas páginas hay que entenderlo más como "pistas humildes para llegar al final", "luces que intentan iluminar la travesía".. que como "respuestas completas, inamovibles...".

Lo que se ofrece no son "recetas", sino sencillas pistas en el camino del servicio pastoral. Es necesario retornar a las fuentes, volver a las raíces sacerdotales para sacar de ellas las fuerzas que hoy precisamos. No hay que dejarse llevar del pesimismo ni de la tristeza. No hay que vivir mirando hacia atrás; es necesario encarar el futuro con lucidez y esperanza, con fortaleza y confianza en el Señor, viviendo el presente en fidelidad al Señor. Ni la resignación derrotista (nada se puede hacer ya), ni creer que cualquier tiempo pasado fue mejor, ni pensar que no estamos haciendo nada son posturas correctas. Hay que evitar un triángulo autodestructivo: "ni creerse un mesías, ni creerse una víctima, ni creerse un agresor o francotirador. Hagamos nuestra la pedagogía del Resucitado en su encuentro con los discípulos en el camino hacia Emaús (cf. Lc 14,13-16). No tengamos miedo porque Cristo está con la Iglesia hasta el final de los tiempos y porque el Espíritu Santo es el aliento para nuestro servicio pastoral.

En este contexto se sitúa este proyecto de vida espiritual del Sacerdote que ha de ser realizado por el Obispo en comunión con el Presbiterio (PDV 79).

\section{I. ¿Qué es un Proyecto de vida?}

El Proyecto no es un conjunto de disposiciones o normas a las que simplemente hay que atenerse y con las que tenemos que conformar nuestra vida, sino que es como "un principio inspirador y dinámico desde el que hay que orientar la vida y el ministerio, así como afrontar el futuro... No se trata simplemente de afirmar y conservar lo que ya conocemos y tenemos. Hay que dar un paso más. Hemos de adentrarnos en la corriente 
de vida que inspira el Espíritu en la Iglesia, en la humanidad, en la historia, y hacerla nuestra ya que la espiritualidad es "el rostro subjetivo de la teología" (H.U.v. Balthasar).

El proyecto ha de dar sentido a la vida del sacerdote, ha de vertebrar su actividad pastoral y ha de orientar su existencia. Este proyecto, expresión de nuestra responsabilidad, tiene sentido cuando se hace como respuesta a la Gracia de Dios que tiene la primacía en cada uno y en todos.

El proyecto global de vida Sacerdotal contiene tres realidades:

* Un ideario que comprende el ser, el obrar y la espiritualidad del presbítero, que ya está presentado.

* Unos objetivos concretos a nivel humano, intelectual, pastoral y espiritual.

* Unos medios para alcanzar esos objetivos.

\section{Dimensiones del proyecto de vida sacerdotal}

El proyecto de vida sacerdotal abarca la totalidad de su persona y de su ministerio pastoral; por tanto ha de tener estas dimensiones: humana, espiritual, intelectual y pastoral.

1. La dimensión humana, porque "sin ella toda formación sacerdotal estaría privada de su fundamento necesario"1.

2. La dimensión espiritual porque es soporte básico para la formación pastoral y es postulada por la necesidad de representar a Cristo Cabeza y Pastor $^{2}$.

3. La dimensión intelectual porque enriquece la espiritualidad del Presbítero al proporcionarle una formulación clara, estimuladora y exigente 3 .

4. La dimensión pastoral porque unifica y da un sentido concreto a todas las demás dimensiones ya que éstas han de tener un marcado y esencial acento pastoral ${ }^{4}$.

Nos centramos en la dimensión espiritual, presuponiendo las otras dimensiones.

\footnotetext{
1 Sínodo de 1990.

2 Juan Pablo II: "Pastores dabo vobis", n. 45.

3 Juan Pablo II: "Pastores dabo vobis", n.55.

4 Juan Pablo II: "Pastores dabo vobis", n. 57.
} 


\section{Objetivos del Proyecto espiritual del Sacerdote}

Los objetivos más importantes que promueve este Proyecto son los siguientes:

1. Ayudar a los Presbíteros a identificar su específica espiritualidad5.

2. Estimular al Presbítero a alcanzar la santidad6.

3. Favorecer la construcción en el Presbiterio diocesano de "la forma de Vida Apostólica"7.

4. Recuperar la Eucaristía como centro de la espiritualidad del Sacerdote 8 .

5. Potenciar el Presbiterio, en el seno de la Iglesia Particular, como institución al servicio de los Sacerdotes?

5 Cong. para la evangelización de los pueblos: "Es preciso que los sagrados ministros conozcan exactamente lo específico de la espiritualidad sacerdotal para que puedan renovarse continuamente...; en la espiritualidad sacerdotal está incluida, a nuevo título, la vocación a la santidad, como signo e instrumento personal de Cristro... Sin una fuerte vida espiritual y un generoso servicio apostólico, en íntima unión con Cristo Sacerdote y Buen Pastor, hasta llegar a la cumbre de la santidad, en la línea de la espiritualidad que les es propia, es imposible realizar la identidad sacerdotal y perseverar con generosidad en el ministerio" "Guía pastoral para los sacerdotes diocesanos...", n.19).

${ }^{6}$ Juan Pablo II muestra la naturaleza de la santidad que es "intimidad con Dios; imitación de Cristo, pobre, casto, humilde; amor sin reservas a las almas y donación a su verdadero bien; amor a la Iglesia que es santa y nos quiere santos, porque ésta es la misión que Cristo le ha encomendado. Cada uno de vosotros debe ser santo, también para ayudar a los hermanos a seguir su vocación a la santidad" ("Homilía a 5.000 seminaristas de todo el mundo"; cf. PDV 33).

7 "La Congregación para la evangelización..." explica la naturaleza de la vida apostólica: "seguir a Jesús, dejando todo por Él, y en estar dispuestos a ejercer el ministerio por todas partes, con un espíritu de fraternidad y ayudándose mutuamente como miembros de una familia sacerdotal, bajo la guía de su Obispo" ("Guía pastoral para los sacerdotes diocesanos...", n. 20).

8 Juan Pablo II: "Si la Eucaristía es centro y cumbre de la vida de la Iglesia, también lo es del ministerio sacerdotal. Por eso, con ánimo agradecido a Jesucristo, nuestro Señor, reitero que la Eucaristía "es la principal y central razón de ser del sacramento del sacerdocio, nacido efectivamente en el momento de la institución de la Eucaristía y a la vez de ella" (Carta apost. Dominicae Cenae, 24-II-1980, 2) (“Ecclesia de Eucharistia", n. 31).

9 Juan Pablo II enseña que "el Presbiterio en su verdad plena es un "mysterium": es una realidad sobrenatural porque tiene su raíz en el sacramento del Orden" ("Pastores dabo vobis", n. 74). 


\section{CAPÍTULO DÉCIMO: ITINERARIO DE LA ESPIRITUALIDAD DEL SACERDOTE}

"El cuidado de la vida espiritual se debe sentir como una exigencia gozosa por parte del mismo sacerdote, pero también como un derecho de los fieles que buscan en él -consciente o inconscientemente- al "hombre de Dios", al consejero, al mediador de paz, al amigo fiel y prudente y al guía seguro en quien se pueda confiar en los momentos más difíciles de la vida para hallar consuelo y firmeza"1.

Es necesario adherirnos cada vez más a Jesucristo, fijar nuestros ojos en Él y retomar un camino de conversión y de renovación que sea "un caminar desde Cristo", porque Él mismo ha venido primero a nuestro encuentro y nos acompaña en el camino (cf. Lc 24,13-22).

¿Cómo hemos de vivir la espiritualidad? ¿qué señales tenemos en este camino para no equivocarnos? ¿con quiénes tengo que recorrer este camino?, ¿qué ayudas tenemos?

\section{Presupuestos teológicos}

\subsection{La Primacía de la gracia de Dios}

En la vida espiritual, en el camino de la santidad y en la acción pastoral la gracia de Dios tiene la primacía porque el Espíritu Santo es el protagonista de la espiritualidad (PDV 27), de la evangelización (EN 75) y de la santidad del Presbítero (NMI 30). En el Cristianismo, la primera palabra es Dios, Jesucristo, el Reino, la Gracia; la segunda palabra es el Hombre, la fe, la conversión...

\subsection{La colaboración del hombre con la Gracia divina}

Dios nos pide y hace posible nuestra colaboración real con su gracia. Ahora bien para que podamos colaborar de forma correcta con la gracia divina son necesarias unas condiciones subjetivas: interiorizar y hacer

${ }^{1}$ Congregación para el Clero: "Directorio para el ministerio y la vida de los Presbiteros", n. 39). 
propio el Proyecto, al menos en sus líneas esenciales, y estar dispuesto a realizarlo; estas condiciones son necesarias, pero son insuficientes; y unas condiciones objetivas: tener una visión correcta del ministerio pastoral, cultivar la caridad pastoral y realizar el ministerio pastoral con "espíritu" y "unción”.

\subsection{En el camino de la vida y del servicio pastoral del Sacerdote}

"Tú, Jesús...eres el milagro que pasa por los senderos de nuestra historia, eres de verdad el Único, el Bueno, el Santo. ¡Ojalá que pudiésemos encontrarte también nosotros! Es necesario saber transfigurar con la mirada de la fe los signos con que Tú, Señor, te presentas a nosotros: no para alimentar nuestra imaginación, sino para completar la realidad, el misterio, lo que verdaderamente Tú eres"2. Contemplemos de cerca a los discípulos de Emaús (Lc.24). Van por el camino comentando con dolor y tristeza la muerte de Jesús en la cruz. Están tristes...

Nuestras vidas y nuestras historias han de hablar entre la memoria del camino ya recorrido y la escucha del tiempo presente. A partir del presente que vivimos, queremos contar al Señor nuestra vida y deseamos volver a escucharte. ¡Tenemos tanto que contarte, Señor! ¡Necesitamos tanto escucharte de nuevo, Señor! El "camino hacia Emaús" nos invita a caminar con la realidad y a dejarnos interpelar por ella.

Jesús en persona se acercó a aquellos discípulos que habían dejado la comunidad de los hermanos y volvían a su aldea. Jesús les va ofrecer y regalar la luz que necesitan para descubrir el sentido de la vida ya que están desilusionados ante lo que había sucedido en Jerusalén: Jesús ha sido crucificado y ha muerto en la cruz.

Como aquellos discípulos, nosotros recibimos hoy la presencia cercana y misericordiosa del Señor. Nuestro tiempo es, por tanto, un "kairós", "un tiempo favorable" porque nos visita el Señor.

Te presentamos, Señor, nuestros sufrimientos y preocupaciones, nuestros cansancios y debilidades y también nuestras esperanzas y alegrías, nuestros gozos y búsquedas. ¡Han pasado ya tantos años en nuestra historia y en nuestro servicio pastoral!

\footnotetext{
2 Pablo VI, Homilía del 14 de Marzo de 1965.
} 
El Señor nos escucha con inmenso cariño y con infinita paciencia; la paciencia del amor. El Señor recoge nuestras palabras, una por una, nuestros sentimientos de confusión y de asombro, nuestra vida, nuestra entrega diaria...

El Resucitado nos descubre que todo lo que estamos haciendo, viviendo, sufriendo y esperando nosotros, las comunidades cristianas y los pueblos es la preparación para un nacimiento extraordinario: "hombres y mujeres nuevos para una nueva humanidad en una nueva creación".

Sigamos caminando al lado del Señor... Sus palabras encienden nuestros corazones. El camino, que se abre ante nosotros, es un camino de fidelidad atenta a las inspiraciones del Espíritu que es el manantial de nuestra espiritualidad llena de Dios y de realidad, comprometida al servicio de los pobres y con el martirio en el horizonte.

Por fin llegan a la aldea. Jesús entró para quedarse con ellos. Y ellos lo reconocieron al partir el pan. La alegría fue inmensa. El Resucitado desaparece para dentro de ellos. Ahora les corresponde a ellos seguir la misión de Jesús. Y se volvieron a Jerusalén y contaron "lo que había pasado en el camino y cómo lo habían conocido al partir el pan" (Lc 24,35). Volvieron a Jerusalén con un animo muy diferente de cuando salieron: en lugar de miedo, valor; en lugar de tristeza, alegría; en lugar de desesperación, esperanza. Si antes no veían en el horizonte de sus vidas perspectivas de futuro, ahora se abre el futuro ante ellos...

También nosotros hemos llegado a nuestro hogar que es la Iglesia, la fraternidad presbiteral. El Señor nos invita a su mesa para ofrecernos su Cuerpo y su Sangre. Allí lo reconocemos. Pero no podemos quedarnos sentados en torno a la mesa del compartir. Hemos de salir a los cruces de los caminos para invitar a todos a participar en el banquete del Señor, ofreciendoles el signo de la solidaridad, de la comunión, de la ayuda fraterna.

Hemos de hacer juntos el camino del retorno. Salgamos de nuestros refugios y, al igual que estos peregrinos, estrenemos una vida nueva en la realidad concreta en la que el Señor nos llama a vivir hoy. El Resucitado nos precede en nuestra "Galilea". No hay que quedarse mirando al cielo. Ha sonado la hora de la misión: "id al mundo entero y haced discípulos míos a todas las gentes...." (Mt 28,19).

Es el momento de asumir una nueva ascética y una nueva espiritualidad. 
La nueva ascética consiste en vivir como la gente común, con un nivel y estilo de vida sencilla, sin privilegios. La nueva ascética, adecuada y testimonial, consiste en vivir voluntariamente en la frontera, en los bordes, en el umbral, en el desierto... Ahora bien es difícil hablar y, sobre todo, vivir una nueva ascética si no se inscribe en una nueva espiritualidad que la contenga y la dote de sentido.

La nueva espiritualidad. Ya hemos escrito de ella. De todos modos, he aquí unas indicaciones:

* la nueva espiritualidad consiste en tener nuevas relaciones con Dios, con los hombres, con la naturaleza, con los objetos. La novedad de estas relaciones se puede resumir así: se trata de una relación amorosa, libre y liberadora, cercana y respetuosa, que no se somete ante los ídolos del poder, del dinero..., que cuida con ternura la vida y deja crecer, que confía y que es fiel.

* la nueva espiritualidad es una espiritualidad desde abajo, en la que "se trata sobre todo de abrirse e iniciar unas relaciones personales con Dios en el punto preciso en que se agotan y cierran todas las posibilidades humanas" (A.Grün y M.Dufner) ante el dolor y el sufrimiento, la persecución y la violencia...Ante nuestras limitaciones humanas, únicamente la gracia de Dios puede cambiarnos.

* la nueva espiritualidad básicamente se caracteriza, según Mons. J.M. Uriarte 3 , por ser:

- Una espiritualidad de confianza, no del optimismo;

- Una espiritualidad de la fidelidad y no del éxito;

- Una espiritualidad del servicio humilde;

- Una espiritualidad del hacer sosegado;

- Una espiritualidad configurada por el celibato;

- Una espiritualidad acompañada y no solitaria;

- Una espiritualidad contemplativa y orante;

- Una espiritualidad de la creatividad y no de mera conservación;

- Una espiritualidad de diálogo y no de confrontación;

- Una espiritualidad profética, pero tierna y compasiva como la de Jesús.

3 Juan María Uriarte: "Ministerio Presbiteral y espiritualidad", San Sebastián; pp. 34-52. 


\section{2. ¿Cómo ha de vivir el Presbítero su espiritualidad?}

\subsection{En las distintas etapas de su vida}

En la juventud: ha de potenciar la oración personal, participar en los encuentros sacerdotales, tener dirección espiritual, injertarse bien en el Presbiterio, no descuidar su formación permanente, ni dejarse seducir por lo aparente, lo efímero.

En la madurez: ha de optar por un sano realismo, por un moderado optimismo, por una comunicación fraterna con los hermanos, por una búsqueda constante de motivaciones y medios para la propia misión, por una vivencia más comunitaria del ministerio, por una cercanía gozosa a los pobres y a los enfermos, por una oración confiada a Dios. Es la hora de "dejar que Dios sea Dios en su vida y en su ministerio".

En la senescencia: ha de volverse al Señor y confiarle la vida pasada, entregarle el presente y ofrecerle el futuro. Es la hora de decir a Dios: "Señor, hágase tu voluntad, no la mía". Es el momento de decir con palabras de Pablo: "ahora me alegro por los padecimientos que soporto por vosotros, y completo en mi carne lo que falta a las tribulaciones de Cristo" (Col 1,24). Es la hora de "la confirmación serena y alentadora de la misión que todavía están llamados a llevar a cabo en el presbiterio".

Ante la jubilación. Los jubilados deben ser ayudados y estimulados a "continuar, de manera serena y decidida, su servicio a la Iglesia; a no aislarse de la comunidad ni del presbiterio; a reducir la actividad externa para dedicarse a aquellos actos de relación pastoral y de espiritualidad personal, a seguir siendo miembros activos en la edificación de la Iglesia, esencialmente en virtud de su unión con Jesucristo doliente y con tantos hermanos que en la Iglesia participan en la Pasión del Señor".

En el atardecer de la vida. Los presbíteros han de seguir rezando así: "y sólo pido no pedirte nada, estar aquí, junto a tu imagen muerta, ir aprendiendo que el dolor es sólo la llave santa de tu santa puerta" (Himno Litúrgico). Es la hora en que "el Presbiterio debe mostrarles su reconocimiento y gratitud por el fiel servicio que han prestado a Cristo y a la Iglesia y una solidaridad particular dada su situación".

En la hora de pasar de este mundo al Padre. Algún sacerdote ha de estar presente, acompañarle y ayudarle a pasar con fe y esperanza de esta tierra a la Casa del Padre. Le ofrecerá los sacramentos de la Iglesia: 
Reconciliación, Eucaristìa, Unción de Enfermos, lo rodeará de afecto y oración y lo confiará a la misericordia del Padre para que salga de este mundo en paz al encuentro del Señor. Acompañará a su familia 4 .

\subsection{Más allá del intimismo, el compromiso}

Es cierto que el Sacerdote debe preocuparse de ser bueno, pero no ha de desentenderse de los problemas y de las necesidades de los demás. Es verdad que debe ser santo, pero al mismo tiempo debe comprometerse al servicio del Reino de Dios. Es cierto que tiene que cumplir los compromisos adquiridos, pero también ha de insistir en la dimensión profética de su misión. El centro de la fe cristiana puede resumirse en esta frase del Evangelio de San Juan: "Y el Verbo se hizo carne, y habitó entre nosotros" (Jn 1,14). No podemos silenciar ni prescindir del Misterio de la Encarnación del Hijo de Dios en una sociedad que prescinde de Dios.

Nuestra espiritualidad ha de huir no sólo de un secularismo que borra a Dios del horizonte humano, sino también de un espiritualismo puramente teórico, sentimental, individualista que pintaría a Dios ajeno a la historia y convertiría a la religión en una fuga de la realidad. El Cristianismo no es compatible con el reduccionismo temporalista de un secularismo a ultranza, ni lo es con la evasión espiritualista que busca refugio en un "sagrado" trascendente.

Nuestra espiritualidad no es huida del mundo, sino una responsable y gozosa acogida de nuestra tarea en el mundo que Dios nos ha confiado $\mathrm{y}$ ha puesto en nuestras manos.

"Para Jesús no hay acceso posible a Dios fuera de la dedicación y del compromiso con el Reino de la fraternidad en la que cada hombre se aproxima al necesitado y se hermana con él, en lugar de pasar de largo ante los caídos en la cuneta de la historia... ¿Cómo buscar a Dios? No en el espiritualismo, sino en el Espíritu Santo. A Dios se le encuentra "humanizado" en Jesucristo, hecho en Él solidario con nosotros y hermano nuestro, e interpelándonos a la solidaridad y la fraternidad". ¿Cómo buscar a Dios? Buscando efectivamente "trascendencia y verticalidad" pero en el clamor de los sufrientes y oprimidos (Mt 25,37), y no en dioses hechos a imagen y semejanza del anhelo humano (cf. 1 Jn 3,14 ). "Si yo falto al amor o falto

4 Juan Pablo II: “Pastores dabo vobis", nn. 76-77. 
a la justicia, me aparto infaliblemente de Ti, Dios mío, y mi culto no es más que idolatría. Para creer en Ti tengo que creer en el amor y en la justicia (Miq 6,8)... fuera de ellas es imposible que te encuentre. Y quienes las toman por guía están en el camino que lleva hasta Ti” (H. de Lubac).

"La oración y adoración, el culto y la celebración tienen su lugar necesario e imprescindible en la vida de fe individual y comunitaria... pero ha de ser una fe en el único Dios auténtico, que le reconozca como lo que es y le honre como Él quiere ser honrado: como Señor de todo y Padre de todos, en la vivencia práctica de la filiación en la fraternidad" (Cristianisme i Justicia).

\subsection{Más allá del ritualismo, la mística}

La mística nos adentra en la experiencia del misterio, explicado por la Teología. Es "la cara subjetiva de la dogmática" o "la experiencia de la fe" (U.v. Balthasar).

Unas sencillas preguntas: ¿tenemos necesidad de convertirnos?, ¿tenemos la capacidad de asumir la debilidad y la ancianidad?, ¿tenemos necesidad de aprender el "ars moriendi"?, ¿somos capaces de asumir el nuevo rol en la Iglesia y en la sociedad?

La espiritualidad del Sacerdote diocesano secular es una realidad no meramente ascética o ética, sino también mística ya que implica una profunda experiencia del Dios que nos ha revelado Jesús, el Hijo de Dios hecho hombre.

¿De qué mística se trata?

Una mística que no aleja de la encarnación, de la solidaridad y del compromiso en el mundo. Una mística de búsqueda, de resistencia activa, de perseverancia en toda circunstacia. Por eso, el Sacerdote ha de conjugar lo más alto de la mística con lo más alto de la entrega de sí mismo en la acción. "No sólo la oración es el alma del apostolado, sino que el apostolado es el alma de la oración" (A.Cencini). K. Rahner decía que "el cristiano del s.XXI será un místico, alguien que ha experimentado algo, o ya no será nada".

\subsection{Más allá del aislamiento, el camino comunitario}

"Hablar de la caridad pastoral" en relación al Obispo, al Presbiterio diocesano y a la Iglesia local significa delinear los rasgos esenciales de la 
"espiritualidad del sacerdote diocesano"... La vida espiritual del sacerdote diocesano no puede tener como referencia "primaria" alguna autoridad o alguna "fuente" extra-diocesana.... El sacerdote diocesano no puede sustancialmente evadir la necesidad de hacer comunión con su Obispo, su Presbiterio y con la parte del Pueblo de Dios a la que es enviado. Ésta es la estructura de la espiritualidad del sacerdote diocesano, que hay que llenar con ocasiones, encuentros, oración, momentos comunitarios... Otras espiritualidades podrán sin duda sustentar al sacerdote y hasta enriquecer su caridad pastoral. La "Pastores dabo vobis" afirma que la pertenencia y la dedicación del sacerdote a la propia Iglesia particular deben considerarse como "valor espiritual" (n. 31).

Esto no significa que el sacerdote diocesano tenga que vivir encerrado en su diócesis; ha de estar dispuesto a salir físicamente de la propia Iglesia local para "ir a misiones". Ahora bien, "la misión ad gentes" debe ser entendida en la implicación misionera de las Iglesias locales. En este sentido, debería ser la Iglesia Local la que envía a sus presbíteros por un cierto tiempo a otras Iglesias hermanas de países lejanos.

Este camino comunitario tiene varias expresiones y manifestaciones, que exponemos a continuación.

A) Insertados en el Pueblo de Dios. "Quiso el Señor santificar y salvar los hombres no individualmente y aislados entre sí, sino constituir un pueblo que le conociera en la verdad y le sirviera santamente" (LG 9). Los sacerdotes diocesanos viven su específica espiritualidad no como una realidad separada, sino en el seno del Pueblo de Dios y en comunión eclesial5.

La espiritualidad del Presbítero diocesano secular está arraigada en el Pueblo de Dios de tal modo que el Sacerdote vivirá su espiritualidad de forma compartida con los miembros del Pueblo de Dios y, en particular, con los agentes de pastoral y se dejará evangelizar por los pobres y los valores culturales y religiosos de los pueblos.

La dinámica espiritual es un proceso personal, pero se desarrolla en un entorno comunitario, en íntima correlación y en interdependencia mutua.

5 Pablo VI manifestó que "hace falta hacerse hermanos de los hombres en el momento mismo que queremos ser sus pastores, padres y maestros" (E.S. n. 647). De igual modo, Juan Pablo II enseña que "el sacerdote debe crecer en la conciencia de la profunda comunión que lo vincula al Pueblo de Dios; él no sólo está al frente de la Iglesia, sino ante todo en la Iglesia. Es hermano entre hermanos" (PDV 74). 
La vida del cristiano, y aún más la del presbítero diocesano, no es un avance en solitario hacia la santidad. Es un camino recorrido en solidaridad, la solidaridad eclesial del Pueblo de Dios. El Presbítero, como cristiano y aún más como pastor, no puede prescindir de la dinámica comunitaria: se trata de llegar a la meta a la cabeza del rebaño encomendado y congregado.

El sacerdote está al servicio de la comunidad, pero a su vez se encuentra sostenido por la comunidad. Éste tiene necesidad de la aportación del laicado, no sólo para la organización y la administración de su comunidad, sino también para la fe y la caridad; existe una especie de ósmosis entre la fe del presbítero y la fe de los otros fieles. Las familias cristianas y las comunidades de gran fervor religioso a menudo han ayudado a los sacerdotes en los momentos de crisis".

No tengamos miedo ni reticencia alguna cuando se habla, se proponen o se ponen en marcha formas comunitarias nuevas de vivir la espiritualidad. Se trata de señalar un horizonte nuevo y de establecer unos criterios-marco que sirvan de guía para vivir con mayor autenticidad la espiritualidad sacerdotal.

\section{B) Unidos fraternalmente en el Presbiterio Diocesano}

Todos los presbíteros "próvidos cooperadores del orden episcopal y ayuda e instrumento suyo, forman, junto con el Obispo, un solo Presbiterio y una sola familia cuyo padre es el Obispo (PO 8). Ser presbítero es pertenecer a un colegio que, en torno al Obispo, realiza la tarea ministerial al servicio de una Iglesia diocesana determinada. La razón de la colegialidad presbiteral no es de tipo funcional, estratégico o práctico, sino de tipo sacramental ya que es fruto de la Ordenación. Hay un solo ministerio porque solamente hay un Cristo que es cabeza y pastor al que se representa sacramentalmente (Julio Ramos Guerreira).

A la luz de estas palabras del Concilio, podemos hacernos unas preguntas muy sencillas: ¿somos una colectividad más que una fraternidad? Dada la edad media del clero ¿nuestra pastoral se caracteriza por la inercia, el individualismo y la rutina?, ¿con nuevos proyectos no corremos el riesgo de aumentar el número de "gente quemada"?, ¿hay sacerdotes que viven y ejercen "por libre"? Vemos la necesidad de la pastoral de conjunto, pero ¿la llevamos a la práctica? 
El Presbiterio, en su verdad plena, es un "mysterium", una realidad sobrenatural, porque tiene su raíz en el sacramento del Orden. Es el sacramento del Orden su fuente, su origen. Es el lugar de su nacimiento y de su crecimiento" (PDV 74). El Presbiterio tien su raíz en el sacramento del Orden, no en el Derecho. El Derecho lo configurará, pero su raíz es el Sacramento del Orden. "El Presbiterio diocesano no es, por tanto, una determinación estructural, sino una realidad sacramental en el interior de la Iglesia Particular. Se es presbítero para la Iglesia universal pero desde la Iglesia Particular"6.

El Presbiterio es la "familia sacerdotal" (ChD 28; PDV 74), "un hecho evangelizador"7, "el lugar privilegiado donde el sacerdote debiera poder encontrar los medios específicos de santificación y de evangelización y donde pudiera ser ayudado a superar los límites y debilidades propios de la naturaleza humana".

El presbiterio es lugar sacramental donde nace el presbítero. El presbiterio es creado por el sacramento del Orden, y el presbiterio, presidido por su cabeza sacramental que es el Obispo, recibe a los candidatos a ser presbíteros. El presbítero nace co-presbítero. Cuando en el ejercicio de la misión pastoral presbiteral el prefijo "co-" no funciona, el presbítero tampoco funciona.

Las consecuencias que se derivan del Presbiterio como "mysterium" son importantes:

- La no coordinación, el estar al margen del Presbiterio no va contra el derecho o la moral, sino contra el ser del Presbiterado. Por eso, los presbíteros no vivirán su sacerdocio de forma aislada e individualista, sino en comunión fraterna dando y recibiendo el calor de la amistad, de la asistencia afectuosa, de la comprensión, de la corrección fraterna.

- No hay presbíteros, hay co-presbíteros. Esto no significa que haya que sustituir la responsabilidad personal de un ministro ordenado por los colectivos ya que la responsabilidad del ministro ordenado es personal, y nunca un colectivo puede sustituir lo que es una misión personal; pero es personal en el seno de un colegio. Por otra parte, co-presbítero quiere

${ }^{6}$ Lorenzo Trujillo: "El Presbítero en el presbiterio" (Espiritualidad del Presbítero diocesano secular. Simposio; p. 486).

7 Documento de "Puebla" (Méjico), n. 663. 
decir que el Presbiterio es de la Iglesia Particular para la Iglesia universal en la pequeña unidad pastoral de la Iglesia. Además, ser y actuar como copresbítero influye mucho en el tema "de la sucesión" en la que se descubre enseguida hasta qué punto el presbítero es co-presbítero o autárquico. Finalmente, la co-presbiterialidad no sólo implica la complementariedad en la sucesión, sino también la complementariedad en la simultaneidad; en este sentido, el co-presbítero es una necesidad para todos. No es cuestión de ética, estética, moral, eficacia...sino de configuración íntima, de sacramentalidad... Si para emprender una actividad pastoral debo separarme, romper con el Presbiterio...quiere esto decir que mi planteamiento está mal hecho o que mi tarea es inaceptable.

- La estructura beneficial hace difícil una vivencia co-presbiteral, que es posible vivirla y es obligatorio que la vivamos ya hoy mismo.

- Las formas de vida compartida: equipos pastorales, convictorios, arciprestazgos y unidades pastorales (en su elemento presbiteral), la asociación de presbíteros...son mediaciones para construir "presbiterios". Todas estas formas de vida compartida deben ser "un camino a hacer presbiterio total".

En un ambiente postmoderno donde la fe cristiana no es ya una evidencia cultural, los presbíteros diocesanos harán bien en procurar medios de reencontrarse para orar unidos, compartir su ministerio y entrar en una dinámica de formación permanente.

\section{La ayuda que ofrece el Presbiterio a los Presbíteros:}

El Presbiterio ha de ofrecer a los Sacerdotes los medios de espiritualidad y las diversas formas de ayuda que puedan facilitarles "la vida apostólica".

Esta ayuda se ofrece a los Presbíteros para conseguir estos objetivos:

Reavivar la Oración y la Contemplación mediante:

a) Los Retiros Espirituales de Adviento, Cuaresma y Pascua.

b) Los Ejercicios Espirituales anuales en el inicio del Verano.

c) Las Reuniones mensuales arciprestales de Oración y de Formación Permanente.

d) Los servicios de la Delegación diocesana de Liturgia.

e) Los encuentros sacerdotales diocesanos en los que siempre hay espacios de oración. 
Fortalecer la santidad, la fraternidad y la colaboración interpersonal mediante:

a) La Convivencia Sacerdotal en Navidad.

b) La celebración de la Misa Crismal.

c) Las reuniones del Obispo con los Sacerdotes Jóvenes.

d) El Homenaje a los Sacerdotes en sus Bodas Sacerdotales en la celebración de San Juan de Ávila.

e) La ayuda fraterna en tareas pastorales.

Fomentar la salud integral de los Presbiteros mediante:

a) La atención a los enfermos, jubilados, solos.

b) La atención a los problemas humanos de los Sacerdotes.

c) Los servicios de la Vicaría Episcopal del Clero.

d) Los servicios de la Casa Diocesana de Ejercicios Espirituales.

e) Los servicios de la Casa Sacerdotal Diocesana.

f) Un tiempo semanal de descanso.

Promover un ejercicio más comunitario del Ministerio Pastoral mediante:

a) Las reuniones arciprestales.

b) El Cursillo anual de Formación Permanente.

c) La Misión "in solidum".

d) La participación de los Presbíteros en los Organismos diocesanos de comunión y de participación: Consejo Presbiteral, Consejo diocesano de Pastoral, Consejo diocesano de Economía...

e) Los servicios de la Vicaría Episcopal de Pastoral y Delegaciones Diocesanas.

Potenciar la relación de los Presbíteros con los Laicos mediante:

a) La presencia de los laicos en los organismos de comunión y de corresponsabilidad de la Diócesis, Arciprestazgo y Parroquia, así como en las Catequesis de la Comunidad, en los Movimientos de Acción Católica...

b) El apoyo a las Instituciones que promueven la formación de los Laicos. 
c) La oración apostólica: oración por las personas confiadas y con ellas.

Fomentar la formación permanente de los Presbiteros mediante:

a) El Cursillo diocesano anual de formación permanente.

b) La Formación permanente mensual en los Arciprestazgos.

c) Los Cursos de actualización para sacerdotes en Universidades Pontificias.

d) Las Conferencias "FE-CULTURA" anuales.

e) El Encuentro teológico de los Seminaristas.

f) Cursillos organizados por Delegaciones Episcopales de la Diócesis.

C) Viviendo, orando, formándose y actuando unidos en el Arciprestazgo

El Arciprestazgo es hogar de fraternidad, taller para la misión, ámbito de oración compartida, lugar de formación permanente para todos, espacio donde se comparte la acción pastoral y se revisa. Trabajemos todos para que sea realidad ese Arciprestazgo.

Sería bueno que se establecieran en todos los Arciprestazgos el "Día del Arciprestazgo" como signo de comunión fraterna, de comunicación, de ayuda, de corresponsabilidad pastoral y de oración compartida y como llamada a potenciar en todos la conciencia de Arciprestazgo.

De igual modo sería bueno que surgieran "las fraternidades apostólicas", formadas por Sacerdotes, Religiosos, Religiosas y Laicos los cuales, desde la inserción, la gratuidad y la contemplación, comparten la oración, la tarea pastoral, la formación permanente, y son expresión viva de este camino comunitario de espiritualidad en el Arciprestazgo.

D) Las Unidades Pastorales

La puesta en marcha de las Unidades Pastorales se hará desde las claves de la fraternidad, la corresponsabilidad y la misión. La Unidad Pastoral es una forma concreta de aplicar en la Diócesis el contenido del canon 374, 2 del CIC que dice: "para facilitar la cura pastoral mediante una actividad común, varias parroquias cercanas entre sí pueden unirse en grupos peculiares". 
Con ello, se pretende buscar una mejor atención pastoral a las Comunidades Cristianas, una mayor eficacia pastoral, una más adecuada distribución de los agentes de pastoral y una mejor utilización de los medios. Esto va más allá de la ayuda y colaboración que pueda darse entre parroquias vecinas ya que con ellas se fomentan la comunión y la corresponsabilidad pastoral, se valoran y acogen los carismas, se abren espacios de participación a las Religiosas y Laicos, se promueven los ministerios y se suscitan los agentes de pastoral.

Estas Unidades son el espacio donde los Presbíteros viven su espiritualidad en comunión con otros Presbíteros, Religiosos, Religiosas y Laicos cristianos, y donde comparten la tarea pastoral al servicio de los pueblos en el ámbito del Arciprestazgo.

E) Las Asociaciones sacerdotales y los Movimientos y Grupos de espiritualidad

Los Presbíteros seculares tienen derecho a asociarse (CIC, cn.215) y, por tanto, a pertenecer a asociaciones clericales que les ayuden a alcanzar los fines coherentes con el estado clerical (CIC cn. 278,1; cf. PO 8). "Todas las formas de "fraternidad sacerdotal" aprobadas por la Iglesia son útiles no sólo para la vida espiritual, sino también para la vida apostólica y pastoral (PDV 81) de los presbíteros.

La razón de ser de una Asociación Sacerdotal es ayudar a los presbíteros a vivir más plenamente su específica espiritualidad, su vocación y su misión en la Iglesia Particular y en su Presbiterio8.

\subsection{Más allá del formalismo, el camino personal}

En nuestros días, el sacerdote ha de tener la valentía y el coraje de decidirse personalmente y cada día por el Señor y esto forma parte de su espiritualidad. Cada Sacerdote responde a su vocación cuando elabora y articula su proyecto personal de vida y se compromete con él.

${ }^{8}$ La Conferencia Episcopal Española afirma que "el hecho de vivir encuadrados en otras instituciones eclesiales surgidas al hilo de la historia, por la acción del Espíritu, no nos dispensa del esfuerzo por integrarnos en la Iglesia Particular constituyente del ser mismo de la Iglesia" ("Testigos del Dios vivo", n. 41). 
A) Los medios de espiritualidad

"Para que los presbíteros puedan fomentar la unión con Cristo en todas las circunstancias de la vida, además del ejercicio consciente de su ministerio, cuentan con los medios comunes y particulares, nuevos y antiguos, que nunca deja de suscitar en el Pueblo de Dios el Espíritu Santo, y que la Iglesia recomienda e incluso manda alguna vez, para la santificación de sus miembros" (PO 18). La espiritualidad del Presbítero debe encarnarse en la existencia de cada presbítero a través de la liturgia, la oración personal, el tenor de vida y la práctica de las virtudes cristianas; todo esto contribuye a la fecundidad de la acción ministerial".

B) ¿En qué consisten estos medios?

Estos medios no están separados ni yuxtapuestos al Ministerio pastoral, sino que son "la forma y la hondura del ejercicio ministerial que toma la vida íntegra del Presbítero, y no sólo parte de ella; son ya ejercicio del ministerio; en ellos se realiza muy especialmente la ministerialidad del Presbítero" (L.Trujillo). Estos medios han de estar en sintonía con el "fondo bautismal común" y con el "perfil propio" de la espiritualidad del Presbítero para evitar incoherencias.

Estos medios deben ser también entendidos como las fuentes vivas de la espiritualidad, de las que se alimenta la vida de la Iglesia y toda vida cristiana, también la sacerdotal.

C) ¿Cuáles son estos medios?

Siguiendo de cerca las enseñanzas del Concilio Vaticano II (cf. PO 18), proponemos una serie de medios que los Presbíteros han de tener presentes en su vida espiritual, en esa llamada al modelo apostólico y su seguimiento.

\section{a) La Eucaristía}

La celebración diaria (PO 13) de la Eucaristía es "centro y raíz" (PO 14), "fuente y culmen" (LG 21) de la vida y del ministerio del sacerdote y debe ocupar para el sacerdote "el lugar verdaderamente central de su ministerio" PDV 26) porque en ella está contenido todo el bien espiritual de la Iglesia. En la Eucaristía, Él se hace nuevamente presente en medio 
de sus discípulos, explica las Escrituras, hace arder el corazón e ilumina la mente, abre los ojos y se hace reconocer (cf. Lc 24,13-35).

La adoración eucarística permite al Sacerdote asimilar las actitudes eucarísticas (cf. PDV 48). "Entretenerse en coloquio íntimo de adoración frente al Buen Pastor, presente en el Santísimo Sacramento del altar, constituye una prioridad pastoral superior con mucho a cualquier otra. El sacerdote, guía de una comunidad, debe poner en práctica esta prioridad para no caer en la aridez interior y convertirse en canal seco, que a nadie puede ofrecer cosa alguna"9.

b) La Liturgia de las Horas

El Sacerdote ha recibido el privilegio de "hablar a Dios en nombre de todos", de hacerse "como la boca de toda la Iglesia" (S. Bernardino de Siena). El rezo diario de las Horas, oración de la Esposa de Cristo y signo sacramental de la plegaria sacerdotal de Cristo, ocupará un puesto privilegiado en la vida del sacerdote y en las reuniones presbiterales. Es importante rezar con la Comunidad Cristiana parte de la liturgia de las horas.

c) La Palabra de Dios

El Sacerdote "necesita acercarse a la Palabra con un corazón dócil y orante, para que ella penetre a fondo en sus pensamientos y sentimientos y engendre dentro de sí una mentalidad nueva: "la mente de Cristo" (1 Cor $2,16)^{10}$.

La Lectura espiritual asidua enriquece la espiritualidad del Sacerdote. Por eso debe ocupar un espacio suficiente y un tiempo adecuado en su vida. El Sacerdote debe tomar la firme decisión de dedicar un tiempo todos los días a leer y meditar la Palabra de Dios, especialmente el Evangelio del día. "Dos cosas matan el alma: la desesperación y la falsa esperanza. Es el "evangelio de la comunicación", es decir, Cristo mismo, el que hizo oír al sordo y hablar al mudo" (Mc 7,37), quien nos abre el camino de la esperanza y nos mantiene en él" (San Agustín).

\footnotetext{
${ }^{9}$ Congregación del Clero: "El Presbítero, Pastor y Guía de la Comunidad Parroquial", n.11.

10 Juan Pablo II manifiesta que "no cabe duda de que la primacía de la santidad y de la oración sólo se puede concebir a partir de una renovada escucha de la Palabra de Dios" (NMI 39).
} 
d) La oración

Una auténtica vida espiritual exige que todos, en las diversas vocaciones, dediquen regularmente, cada día, momentos apropiados para profundizar en el coloquio silencioso con Aquel por quien se saben amados, para compartir con Él la propia vida y recibir luz para continuar el camino diario. Es una práctica a la que es necesario ser fieles, porque somos acechados constantemente por la alienación y la disipación provenientes de la sociedad actual, especialmente de los medios de comunicación.

El Presbítero, por tanto, dedicará cada día un tiempo determinado a la oración (PO 18) y buscará "un verdadero encuentro personal con Jesús, un coloquio confiado con el Padre, una profunda experiencia del Espíritu" (PDV 72). Hay que entrar en espacios de oración, verdaderamente contemplativos y comprometidos. "El hombre ya casi no soporta la callada soledad ante Dios y trata de refugiarse en una especie de colectividad eclesial, cuando, en realidad, dicha colectividad ha de edificarse sobre la base de hombres espirituales que hayan tenido un encuentro directo con Dios" (K. Rahner).

El Presbítero cultivará también su oración como "oración del Pastor", como oración apostólica. Misión y contemplación en el presbítero se necesitan mutuamente 11 .

e) La recepción frecuente del sacramento de la Penitencia

"La vida espiritual y pastoral del sacerdote... depende, para su calidad y fervor, de la asidua y consciente práctica personal del Sacramento de la Penitencia..." (Reconciliación y Penitencia, 31). El sacerdote dedicará tiempo suficiente para escuchar las confesiones de los fieles (Juan Pablo II). Hemos de descubrir a Cristo como "misterio de piedad", en el que Dios nos muestra su corazón misericordioso y nos reconcilia plenamente consigo" (NMI 37). Necesitamos recuperar el sentido penitencial de la vida y el sacramento de la penitencia y el sacramento de la unción de los enfermos.

${ }^{11}$ St. Tomás de Aquino escribe: "La falta de disponibilidad para acoger a las ovejas descarriadas, e incluso para ir en su búsqueda y poder devolverlas al redil, sería signo doloroso de falta de sentido pastoral en quien, por la ordenación sacerdotal, tiene que llevar en sí la imagen del Buen Pastor" ("Sobre el Padrenuestro"). 


\section{f) La dirección espiritual}

El Presbítero necesita hoy superar la soledad generada en parte por el temor a compartir experiencias y fracasos en el orden espiritual y en parte también por esa especie de pudor o de timidez que impide abrirse a los demás, y que en el fondo está sujeta a la tentación de no consultar a nadie. De lo que se trata es de que los presbíteros se acompañen verdaderamente en su vida espiritual y pastoral. Por ello, aunque encontrar un "amigo del alma", en el que poder depositar gozos y esperanzas, fracasos y propósitos, sea muy difícil en estos tiempos de subjetivismo y de egolatría, el acompañamiento y la orientación espiritual siguen siendo muy útiles y necesarios para todos ${ }^{12}$.

"Se trata de un medio clásico que no ha perdido nada de su valor para asegurar la formación espiritual y para promover y mantener una continua fidelidad y generosidad en el ejercicio del ministerio sacerdotal" (PDV 81). Es el medio normal del progreso espiritual (PO 18). Ayuda a discernir la voluntad sobre el individuo y el modo de orientar su vida en el mundo conforme al designio de Dios y a las necesidades de cada uno.

\section{g) La devoción a la Stma. Virgen María}

La espiritualidad sacerdotal acoge el testamento de Cristo crucificado, que confió a su Madre al discípulo predilecto y, a través de él, a todos los sacerdotes. Acojamos a María como Madre, formadora de nuestro sacerdocio ya que Ella modela el corazón sacerdotal y protege a los sacerdotes de los peligros, cansancios y desánimos. María es para los sacerdotes la Madre que los conduce a Cristo, a la vez que los hace amar más auténticamente a la Iglesia y los guía al Reino de los Cielos. El rezo diario del "Santo Rosario" y otras formas piadosas son signos de devoción a la Stma. Virgen María ${ }^{13}$.

h) El examen diario de conciencia, unido a la recitación de la oración litúrgica de Completas (PDV 81)

12 Mons. Julián López: "La presencia y la acción del Espíritu Santo en nuestra vida". Carta a los Presbíteros 1998, n.15.

13 Juan Pablo II: "Rosario de la Virgen María", n. 1. 
El Sacerdote, como ser humano que es, está rodeado de fragilidad y está lleno de debilidades y flaquezas. Quiere esto decir que puede cometer el pecado. Por eso necesita examinar a dirio su conciencia. Si le es posible sería muy conveniente que uniera esta revisión espiritual del día al rezo de Completas. Descansará de este modo en la paz del Señor, se cobijará a la sombra protectara y entregará su "espíritu" al Padre.

\section{i) La memoria de los Santos}

El ejemplo de los santos pastores continúa fecundando la historia y, en virtud de la comunión de los santos, llega hasta nosotros y pasará a las generaciones venideras como gracia y bendición de Dios. Es bueno hacer el "memorial" de los buenos y santos pastores de nuestra Diócesis de Coria-Cáceres.

j) La formación permanente -humana, teológica, espiritual, pastoral-

"La vida entera de la persona ha de ser concebida como proceso de formación permanente". Formarse es más que aprender conocimientos, es sobre todo, aprender a ser, estar en continuo crecimiento y en permanente renovación. Formarse es exigencia humana y, sobre todo, exigencia teológica".

La formación permanente constituye otra de las fuentes de renovación espiritual, propuesta por el Concilio Vaticano II. No debe ser descuidada de ninguna forma. Esta formación de los sacerdotes es un deber de los sacerdotes y un derecho de los fieles.

j) El descanso necesario

La "salud integral" de los sacerdotes abarca su descanso físico y psicológico (PO 18; PDV 24-26). Velar y cuidar la salud integral de los presbíteros fomenta la alegría y la calidad de su ministerio. El descuido y la insuficiente atención a las necesidades de los Presbíteros produce en ellos una conciencia de desamparo y puede paralizar el desarrollo de su vida de fe y de su acción pastoral.

Sería bueno que cada Presbítero pudiera contar a lo largo de su vida con "un año sabático", teniendo en cuenta las necesidades de la Diócesis. 


\section{EI Carisma Episcopal y la espiritualidad del Presbítero}

Sin la referencia al carisma episcopal, el sacerdote diocesano no podrá realizar todas las exigencias de su espiritualidad. "Sobre los Obispos recae el grave peso de "fomentar la santidad de sus clérigos..." (ChD. 15), por eso han de preocuparse "de su condición espiritual, intelectual y material, para que ellos puedan vivir santa y piadosamente, cumpliendo su ministerio con fidelidad y éxito" (ChD. n. 16). El presbítero necesita el acompañamiento y la ayuda del Obispo en el camino de su santificación ${ }^{14}$.

14 "El Obispo junto con los sacerdotes de su Presbiterio tiene que recorrer los caminos específicos de espiritualidad en cuanto llamado a la santidad por el nuevo título derivado del Orden Sagrado" (Lineamenta, n. 89 del Sínodo de los Obispos, 2000). 